DOI: $10.20472 /$ IAC.2018.036.052

\author{
JEONG JIN YU \\ Umeå University, Sweden
}

\title{
CLASSIFICATION OF LIFE MOTTOS
}

\begin{abstract}
:
Schwartz and colleagues (2012) identified 19 universal human values related to various beliefs, attitudes, and viewpoints. Peterson and Seligman (2004) categorized 24 character strengths to identify positive traits associated with attitudes, values, and behaviors. The primary motive for these two seminal studies tend to converge around the attempt to identify universal core human values and characteristics leading to attitudes and behaviors. Expanding the scope of focus, the present study sought to shed light on life mottos that are inherently intertwined with human values and traits and to classify them based upon Schwartz et al's (2012) 19 human values and Peterson and Seligman (2004)'s 24 character strengths, as well as 27 newly created categories. The data in the present study included a sample of 10,311 adults ( $54.3 \%$ male, $45.3 \%$ female) who aged 19 to 86 (M $=33.73, \mathrm{SD}=7.46)$. The most commonly categorized life motto was perseverance $(8.7 \%)$, followed by hope $(6.0 \%)$ and zest $(5.6 \%)$. Approximately $13 \%$ were not classified to a single category. Findings suggest that life mottos could be categorized in meaningful ways and they are heavily influenced and shaped by cultural background and socialization.
\end{abstract}

\section{Keywords:}

life motto, value, character, trait

JEL Classification: 131,139 